\title{
Research on the Drunk Driving Traffic Accidents Based on Logistic Regression Model
}

\author{
Shaohua Wang1,2, Yanyan Chen ${ }^{1 *}$, Jianling Huang1,3, Yuyang Zhou1, Yao Lu${ }^{1}$ \\ ${ }^{1}$ Beijing Key Laboratory of Traffic Engineering, Beijing University of Technology, Beijing, China \\ ${ }^{2}$ Tianjin Collaborative Innovation Center of Traffic Safety and Control, Tianjin University of Technology and Education, \\ Tianjin, China \\ ${ }^{3}$ Beijing Transportation Information Center, Beijing, China \\ Email: *cdyan@bjut.edu.cn
}

How to cite this paper: Wang, S.H., Chen, Y.Y., Huang, J.L., Zhou, Y.Y. and Lu, Y. (2018) Research on the Drunk Driving Traffic Accidents Based on Logistic Regression Model. Open Journal of Applied Sciences, 8, 487-494.

https://doi.org/10.4236/ojapps.2018.811039

Received: October 2, 2018

Accepted: November 6, 2018

Published: November 9, 2018

Copyright $\odot 2018$ by authors and Scientific Research Publishing Inc. This work is licensed under the Creative Commons Attribution International License (CC BY 4.0).

http://creativecommons.org/licenses/by/4.0/

Open Access

\begin{abstract}
Most of the current studies on drunk driving accidents focus on law making and public education. However, especially in China, there is less statistical analysis on the severity of drunk driving accidents between driving under the influence of alcohol (DUI) and driving while intoxicated (DWI). 3368 drunk driving related crashes were collected from the blood-alcohol test report in a city of China at 2012 and 2013. After data pre-processing, Chi-square tests were used to analyze the association between different variables and the type of drunk driving. The logistic regression model is conducted to estimate the effect of the variables under DUI and DWI. The results show that Hour of the day, Driver's age, Driver's casualties and Accident area have significant correlation with drunk driving. There was a slightly decrease by 0.995 per year with age and a slightly increase by 1.014 with time in the possibility of DWI. DWI is more likely to cause death in traffic accidents $(\mathrm{OR}=1.316)$ than DUI. Driver's deaths $(\mathrm{OR}=2.346)$ is more likely to happen than the injuries $(\mathrm{OR}=$ 1.910) under DWI cases. These findings show that more attention should be paid to strengthen controls on the DWI. It also can provide important basis for accident prevent, traffic law enforcement and traffic management.
\end{abstract}

\section{Keywords}

Traffic Safety, Traffic Accidents, Drunk Driving, Logistic Regression, Casualties

\section{Introduction}

Drunk driving is a serious threat to road safety worldwide [1] [2]. In 2014, 9967 people were killed due to alcohol-impaired driving in the American, and the to- 
tal cost was estimated to be $\$ 44$ billion [3]. According to statistics from the Traffic Management Bureau under the Ministry of Public Security (MPS) of the People's Republic of China [4], there were 5669 alcohol-related motor vehicles traffic crashes in China, resulting in 2384 deaths, and 5616 injuries in 2014. However, compared to the data of USA [3], it must be pointed out that the statistics are inaccurate because of statistical methods and other reasons [5]. In 2014 , the percentage of fatal crashes involving alcohol rose to $17.5 \%(\mathrm{n}=381)$, representing a 34.9\% $(n=253)$ increase from 2012 in Cambodia [6].

Considering the serious hazards of drunk driving accidents, many resent studies have focused on the influence factor, and detected the driving behavior or public education of drunk driving. Significant risk factors associated with drunk driving are male drivers, private vehicles, the lack of street lighting at night and poor visibility [2]. The cultural values should be considered when designing campaigns against drunk driving [7]. Drunk driving recidivism is more likely to occur among persons who are in situations of socio-economic disadvantage and marginalization [8]. The Alcohol Use Disorders Identification Test (AUDIT) was used to assess the hazardous drinking levels in Yinchuan and compared with the result in Guangzhou, China [9]. A telephone survey showed that knowing how alcohol consumption impairs safe driving and skills, being aware of the associated risks, knowing the traffic regulations concerning drunk driving, and penalizing it strongly are not enough [10]. Using the driving simulator to carry out the experiment, the driver drunk driving behavior can be identified through the vehicle motion parameters and driving operation behavior [11]. Some researchers are considerable differences in aspects such as minimum legal drinking age, blood alcohol limits and the enforcement of alcohol control laws [12].

A legislative amendment was introduced to make "drunk driving" a criminal offence on 1st May, 2011 in China. According the blood alcohol concentration (BAC) limits, the behavior of drunk driver is divided into two groups: driving under the influence of alcohol (DUI, $20 \mathrm{mg} / \mathrm{ml} \leq \mathrm{BAC}<80 \mathrm{mg} / \mathrm{ml}$ ) and driving while intoxicated (DWI, BAC $\geq 80 \mathrm{mg} / \mathrm{ml}$ ). And six years later, some suggestions about drunk driving were presented by Supreme People's Courton May, 2017 in China. A driver with DWI without the severely impaired consequence will not be convicted and punished by the Criminal law. However, the recent research generally focuses on the risk factors surrounding the drivers drinking and not drinking. Especially in China, the factors surrounding with the DUI and DWI are rarely discussed [13]. This study attempts to determine the significant risk factors associated with the type of the drunk driver and give some advice for making the related laws.

First, the drunk driving traffic accidents data are collected and processed in Tianjin municipality of China. Second, the Chi-square tests were used to analyze the association between different variables and the type of drunk driving. Third, the logistic regression model is conducted to estimate the effect of the variables under DUI and DWI. Finally, the conclusions and discussion are presented and followed by references. 


\section{Data Preparation}

\subsection{Data Preparation}

The characters of DUI and DWI are studied statistically with the analysis of the blood test reports from the judicial appraisal organization. All the data is true, reliable and does not involve personal privacy. All data was collected by using VBA technology and analyzed by applying the software SPSS 21. A total of 3368 samples were collected in the reports after traffic accident from the judicial appraisal organization in a city of china. There were including 2551 of DUI and 817 of DWI. As shown in Table 1, different drunk driving influence factors were extracted.

\subsection{Data Description}

September had the largest (326, 9.7\%) and February had the lowest $(214,6.4 \%)$ numbers of drunk driving drivers. As shown in Figure 1, drunk driving accidents

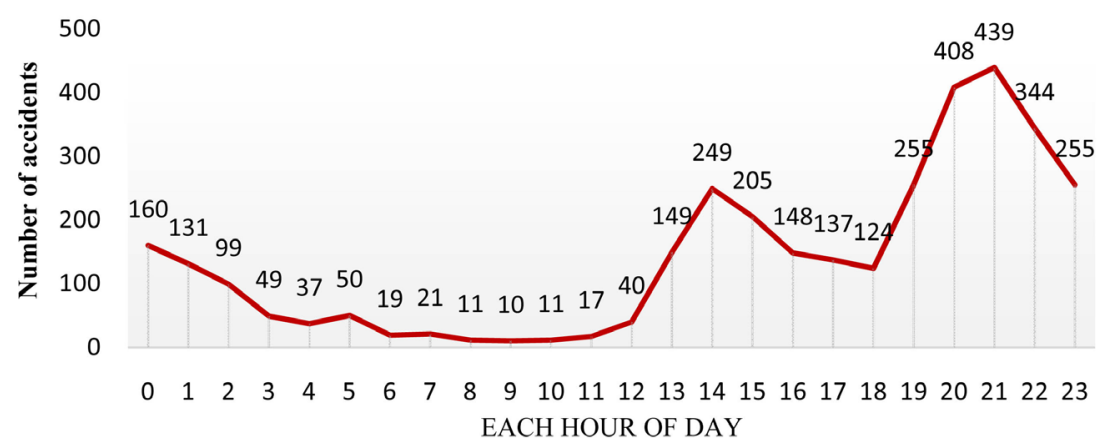

Figure 1. Statistics of drunk drinking accidents.

Table 1. Drunk driving data collection.

\begin{tabular}{ccc}
\hline Influence Factors & Parameter Name & Value \\
Time & Month of the year & 1 to 12 \\
Day of the week & 1 to 7 \\
Hour of the day & 0 to 23 \\
Space & Accident areas & Outer suburb areas $=1 ;$ Suburb areas $=2 ;$ \\
Driver & Urban areas $=3 ;$ Others $=4$
\end{tabular}


mainly occurred at 14:00 - 16:00 on the afternoon $(454,13.5 \%)$ and 19:00 - 00:00 in the evening $(1701,50.5 \%)$. Male drunk driving drivers $(\mathrm{N}=3310)$ accounted for $98.3 \%$. The drivers' age is more concentrated in 20 - 29 (798, 23.7\%), 30 - 39 (767, 22.8\%), 40 - 49 (794, 23.6\%). The vehicle types mainly include car (2061, $61.2 \%)$, two-wheeled motorcycles $(539,16 \%)$ and the two-wheel electric bicycle $(522,15.5 \%)$. The percentage of deaths, injuries and property losses accounts for the total number of accidents are $12.1 \%, 35.2 \%$ and $52.8 \%$.

\section{Methods}

\subsection{Correlation Analysis (CA)}

Significant factors associating with drunk driving are identified by Chi-square test and Spearman test. CA is mainly used for data exploration and analysis to study whether there is a linear correlation and the degree of relationship between different parameters. Different types of parameters have different correlation coefficients. Spearman rank test was applied to verify the correlation. Pearson correlation coefficient was used to analyze the specific relevance on continuous Parameters. The relationship of unordered categorical parameters was studied using Chi-square test. The Chi-square test was used to analyze the contingency coefficient between the parameters. However, the need to pay attention to is that the Fisher exact probabilistic method in crosstabs must be used because theoretical frequency is less than 5 . The two variables bear significant correlation if the $\mathrm{P}<0.05$ by CA.

$$
\chi^{2}=\sum_{i=1}^{k} \frac{\left(A_{i}-n p_{i}\right)^{2}}{n p_{i}}
$$

where $A_{i}$ is the observation frequency of $i$ level, $\mathrm{n}$ is the total frequency, $p_{i}$ is the expected frequency at level $i$, and $k$ is the number of cells. When $n$ is large, the Chi-square statistic approximately obeys the Chi-squared distribution with $k-1$ degrees of freedom.

\subsection{Logistic Regression (LR)}

Logistic regression was developed by statistician David Cox in 1958. The binary logistic model is used to estimate the probability of a binary response based on one or more predictor (or independent) variables (features). It allows one to say that the presence of a risk factor increases the probability of a given outcome by a specific percentage. Logistic regression analyses are built to estimate the effect of different predictor variables on the likelihood of the occurrence of DWI. Assuming that there are $n$ related factors affecting whether accidents occur, denoted by: $x_{1}, x_{2}, \cdots, x_{n}$. The logistic model is [14]:

$$
\operatorname{logit}(y)=\ln \left(\frac{p}{1-p}\right)=a_{0}+a_{1} x_{1}+a_{2} x_{2}+\cdots+a_{n} x_{n}
$$

where $y=(0,1)$ is the type of drunk driving; $p$ is the probability of drunk driving traffic accident's occurrence; $x_{i}(i=1,2, \cdots, n)$ is the parameter associated with 
traffic accident; $a_{0}$ is the constant, and $a_{j}(j=1,2, \cdots, n)$ are regression coefficients.

\section{Results and Discussion}

\subsection{Results}

As shown in Table 2, the results show hour of the day, driver's age, driver's casualties and accident area have significant correlation with drunk driving type.

There was a slightly decrease by 0.995 per year with age and a slightly increase by 1.014 with time in the possibility of DWI. DWI is more likely to cause death in traffic accidents $(\mathrm{OR}=1.316)$ than DUI. Driver's deaths $(\mathrm{OR}=2.346)$ is more likely to happen than the injuries $(\mathrm{OR}=1.910)$ under DWI cases. Compared with the outer suburbs $(\mathrm{OR}=1.590)$, drunk driving is easy to occur at urban areas $(\mathrm{OR}=2.713)$ and suburban areas $(\mathrm{OR}=2.963)($ Table 3$)$.

Table 2. Result of correlation analysis.

\begin{tabular}{cc}
\hline Parameter Name & Correlation Analysis (CA) \\
\hline Month of the year & 0.198 \\
Day of the week & 0.290 \\
Hour of the day & 0.001 \\
Day of the week & 0.271 \\
Driver's gender & 0.983 \\
Driver's age & 0.001 \\
Vehicle type & 0.157 \\
Accident casualties & 0.060 \\
Driver's casualties & 0.001 \\
Accident areas & 0.001 \\
\hline
\end{tabular}

Table 3. Result of logistic regression analysis.

\begin{tabular}{cccccc}
\hline & & & & \multicolumn{2}{c}{ 95\% C.I. for EXP(B) } \\
\cline { 5 - 6 } Parameter Name & B & Sig. & Exp (B) & Lower & Upper \\
\hline Driver's age & -0.005 & 0.048 & 0.995 & 0.990 & 1.000 \\
Hour of the day & 0.013 & 0.017 & 1.014 & 1.002 & 1.025 \\
Driver's casualties & & 0.000 & & & \\
$\quad$ Death & 0.853 & 0.000 & 2.346 & 1.741 & 3.161 \\
$\quad$ Injury & 0.647 & 0.000 & 1.910 & 1.539 & 2.370 \\
Accident areas & & 0.000 & & & \\
Outer suburb areas & 0.464 & 0.474 & 1.590 & 0.447 & 5.664 \\
$\quad$ Suburb areas & 1.086 & 0.096 & 2.963 & 0.826 & 10.635 \\
$\quad$ Urban areas & 0.998 & 0.126 & 2.713 & 0.755 & 9.753 \\
\hline
\end{tabular}




\subsection{Discussion}

China is one of the oldest Liquor birthplaces, which has a long history and profound wine culture. A climate of urging, forcing or gambling to drink has existed at the feast and that is part of the reason for drunk driving. Under such circumstances, it is easy to drink too much beyond the limits of DUI and reach the degree of DWI. The results also prove that DWI (2551) accounted for $75.7 \%$ of all drivers of drunk driving.

Meanwhile, the results show hour of the day, driver's age, driver's casualties and accident area have significant correlation with drunk driving type. The drunk driving involved crashes are more likely to occur after lunch and in the evening. Moreover, more people like to drink the wine at night. This may be due to shorter lunch time than dinner time in a large city. No matter what is the individual dining, the commercial dining together, meeting friends and the birthday party are assembled almost all in the evening. Our results show that the occurring frequency of drunk driving in February is least. Special action of control drunk drinking was launched during the holidays, such as the Spring Festival holiday in January or February.

In general, few people urge female drivers to drink at a banquet. We find that most drunk drinking drivers are male, $98.3 \%$. The possibility of DWI increased with time and decreased with the increase of age. DWI can actually be more harmful for driver's lives and properties. Drunk driving is easy to occur at urban areas $(\mathrm{OR}=2.713)$ and suburban areas $(\mathrm{OR}=2.963)$. This partly is due to the farther away from the city center, the vaster expanse of land and the less chance to involve in lunch or dinner for social events. As a result, DWI can promote the possibility of traffic crashes and lead to more accidents and more severe injuries in those accidents. However, DWI behavior with low severity is not regarded as a crime after May, 2017 in China. This will give some drivers an illusion that they will not be severely punished unless a traffic accident happens. In fact, it is very necessary to forbidden to drink before driving and ceases the lucky psychology.

Although some discoveries have been revealed by this study, there still are some limitations. Further researches need to carry out more detailed investigations with the drunk driving drivers. The data about the social demographic characteristics, drinking locations, drinking patterns and accidents severity should be collected to get a more solid conclusion.

\section{Conclusion}

Considering China's cultural background, it is unrealistic to give up drinking. The best we can do is trying to take appropriate measures according these findings to prevent drunk driving accidents. The traffic police should focus on the male drivers, aged between 20 and 50, who have driven in the afternoon and night. In addition to check the motor vehicle drivers, it should be paid more attention to the drivers of two-wheeled motorcycles and the two-wheel electric bi- 
cycle. DWI can actually be more harmful for people's lives and properties. We should dig further to really understand the characteristic of DWI and put forward corresponding preventing and controlling methods.

\section{Acknowledgements}

This research was funded by the National Key Research and Development Program of China, grant number 2017YFC0803903, the Key Project of the Natural Science Foundation of Tianjin city, grant number 16JCZDJC38200 and the Key Investigation Project of the Tianjin Education Commission, grant number JWDY-20171044. The authors also would like to appreciate the editors and the anonymous reviewers for their constructive comments and advice.

\section{Conflicts of Interest}

The authors declare no conflicts of interest regarding the publication of this paper.

\section{References}

[1] Alcañiz, M., Santolino, M. and Ramon, L. (2016) Drinking Patterns and Drunk-Driving Behaviour in Catalonia, Spain: A Comparative Study. Transportation Research Part F: Traffic Psychology and Behaviour, 42, 522-531. https://doi.org/10.1016/j.trf.2016.09.031

[2] Zhang, G.N., Yaub, K.K.W. and Gong, X.P. (2014) Traffic Violations in Guangdong Province of China: Speeding and Drunk Driving. Accident Analysis and Prevention, 64, 30-40. https://doi.org/10.1016/j.aap.2013.11.002

[3] Niederdeppe, J., Avery, R. and Miller, E.N. (2017) Alcohol-Control Public Service Announcements (PSAs) and Drunk-Driving Fatal Accidents in the United States, 1996-2010. Preventive Medicine, 99, 320-325. https://doi.org/10.1016/j.ypmed.2017.03.009

[4] Traffic Management Bureau and Ministry of Public Security (2014) Annual Report of Road Traffic Crashes in People's Republic of China.

[5] Jia, K., King, M., Fleiter, J., et al. (2016) Drunk Driving Offenders' Knowledge and Behaviour in Relation to Alcohol-Involved Driving in Yinchuan and a Comparison with Guangzhou, China. Transportation Research Part F: Traffic Psychology and Behaviour, 38, 182-193. https://doi.org/10.1016/j.trf.2015.12.011

[6] Bachani, A.M., Risko, C.B., Gnim, C., et al. (2017) Knowledge, Attitudes, and Practices around Drinking and Driving in Cambodia: 2010-2012. Public Health, 144, S32-S38. https://doi.org/10.1016/j.puhe.2016.12.012

[7] Cestac, J., Kraem, S. and Assailly, J. (2016) Cultural Values and Random Breath Tests as Moderators of the Social Influence on Drunk Driving in 15 Countries. Journal of Safety Research, 56, 89-96. https://doi.org/10.1016/j.jsr.2015.12.001

[8] Møller, M., Haustein, S. and Prato, C. (2015) Profiling Drunk Driving Recidivists in Denmark. Accident Analysis and Prevention, 83, 125-131. https://doi.org/10.1016/j.aap.2015.07.015

[9] Jia, K., King, M., et al. (2013) Baseline Study of Alcohol Dependence among General Drivers and Drunk Driving Offenders in Guangzhou, China. Australasian Road Safety Research Policing Education Conference 2013, Brisbane, 28-30 August 2013, 
1-13.

[10] Alonso, F., Pastor, J., Montoro, L., et al. (2015) Driving under the Influence of Alcohol: Frequency, Reasons, Perceived Risk and Punishment. Substance Abuse Treatment, Prevention, and Policy, 10, 11. https://doi.org/10.1186/s13011-015-0007-4

[11] Zhao, X.H., Zhang, X.J., Rong, J. and Ma, J.M. (2011) Identifying Method of Drunk Driving Based on Driving Behavior. International Journal of Computational Intelligence Systems, 4, 361-369. https://doi.org/10.1080/18756891.2011.9727794

[12] Castillo-Manzano, J.I., Castro-Nuño, M., Fageda, X., et al. (2017) An Assessment of the Effects of Alcohol Consumption and Prevention Policies on Traffic Fatality Rates in the Enlarged EU. Time for Zero Alcohol Tolerance? Transportation Research Part F: Traffic Psychology and Behaviour, 50, 38-49.

https://doi.org/10.1016/j.trf.2017.06.017

[13] Huang, H., Wang, X. and Hu, G. (2016) Traffic Safety in China: Challenges and Countermeasures. Accident Analysis \& Prevention, 95, 305-307. https://doi.org/10.1016/j.aap.2016.07.040

[14] Tao, L., Zhu, D., Yan, L., et al. (2015) The Traffic Accident Hotspot Prediction: Based on the Logistic Regression Method. 2015 International Conference on Transportation Information and Safety (ICTIS), Wuhan, 25-28 June 2015, 107-110. 